\title{
Carinal resection for stenotic tuberculous tracheitis
}

\author{
R NATKUNAM, C Y TSE, B H ONG, P SRIRAGAVAN \\ From the Departments of Surgery and Medicine, United Christian Hospital, Kowloon, Hong Kong
}

Tuberculosis of the tracheobronchial tree is usually considered to be secondary to pulmonary tuberculosis and generally resolves with treatment of the primary disease.' We report a case of stricture of the trachea and right main bronchus occurring during antituberculosis treatment.

\section{Case report}

An 18 year old Chinese woman presented in March 1986 with a one month history of increasing wheeze and dyspnoea during exertion. She had been treated elsewhere for pulmonary tuberculosis since November 1985 but admitted poor compliance with treatment. Physical examination showed a very apprehensive woman with inspiratory stridor and cyanosis. A chest radiograph showed mild disease of the right upper lobe compatible with pulmonary tuberculosis. Her respiratory state deteriorated rapidly and endotracheal intubation was attempted without success. An emergency tracheostomy under local anaesthesia also failed as a tracheostomy tube could not be passed. Tracheal stenosis was suspected and a bronchoscopy arranged. The patient was semiconscious and cyanosed. Ventilation was maintained with difficulty by means of a Sander's injector through a partly inserted tracheostomy tube. Blood gas analysis showed pH 6.96, carbon dioxide tension $\left(\mathrm{PCO}_{2}\right) 14.1 \mathrm{kPa}$, and oxygen tension $\left(\mathrm{Po}_{2}\right) 19.6 \mathrm{kPa}$. Rigid bronchoscopy disclosed a tight stenosis of $2-3 \mathrm{~mm}$ diameter about $5 \mathrm{~cm}$ below the tracheostomy site. Repeated dilatations using gum elastic bougies improved ventilation but an endotracheal tube still could not be inserted transorally. Satisfactory ventilation was obtained with a $4.5 \mathrm{~mm}$ portex endotracheal tube inserted via the tracheostomy and pushed past the stenotic segment. At this stage $\mathrm{pH}$ was $7 \cdot 4, \mathrm{PCO}_{2} 6.2 \mathrm{kPa}$, and $\mathrm{PO}_{2} 58.3$ $\mathrm{kPa}$. There was difficulty in maintaining the tube in position and a decision was made to resect the stenosed segment of the trachea. A right sided lateral thoracotomy showed a collapsed upper lobe and mild inflammatory changes around the lower trachea with an apparently normal external diameter. An upper lobe bronchotomy resulted in the expulsion of necrotic material. A fibreoptic bronchoscope inserted via the bronchotomy and advanced retrogradely into the trachea defined the lower limit of the stricture as being $2 \mathrm{~cm}$ above the carina. The stenosed segment of trachea, consisting of five rings, was excised and an end to end anastomosis made. ${ }^{2}$ Ventilation during surgery was maintained via a $7 \mathrm{~mm}$ endotracheal tube introduced directly

Address for reprint requests: Dr $\mathbf{R}$ Natkunam, Department of Surgery, United Christian Hospital, Kwun Tong, Kowloon, Hong Kong.

Accepted 31 August 1987 into the left bronchus. The patient breathed spontaneously as the end of the operation and was extubated six hours later. The postoperative course was complicated by left pneumo if thorax and sputum retention.

Histological examination of the resected specimen ands granulation tissue from the right upper lobe confirmed the diagnosis of tuberculosis. She then had intensive anti-o tuberculosis drug treatment with streptomycin $0.75 \mathrm{~g}$, isoniazid $300 \mathrm{mg}$, rifampicin $450 \mathrm{mg}$, pyrazinamide $1.25 \mathrm{~g}_{c}$ and ethambutol $1 \mathrm{~g}$ a day. One month after the operation the patient again had sputum retention. Spirometry (one second ${ }^{\mathrm{D}}$ forced expiratory volume $\left(\mathrm{FEV}_{1}\right) \mathbf{0 . 4 5 1}$, forced vital capacity (FVC) 1.591, FEV $/$ FVC ratio 28\%), and a flow-volume loopos $(0.55 \mathrm{l} / \mathrm{s})$ recorded at this time indicated severe upper airway obstruction. At bronchoscopy the trachea $8 \mathrm{~cm}$ below the vocal cords was narrowed to about $6 \mathrm{~mm}$ and the right mains bronchial orifice was reduced to a slit. The left main bronchuso was normal. Prednisolone $30 \mathrm{mg} /$ day was started in an effor to minimise the fibrosis. Dilatation of the stenosed trachea $\mathbb{B}$ segment was performed and repeated almost weekly but after= two months no benefit was evident. A bronchogram (figure) showed the stricture extending from the trachea into the righ? main bronchus. An excision of the carina was therefore planned.

At surgery the stricture was found to start about $0.5 \mathrm{~cm}$ above the original suture line and extend about $2 \mathrm{~cm}$ into the right main bronchus. The upper lobe bronchial mucosa wask inflamed. The lower $3 \mathrm{~cm}$ of the trachea was excised and the left main bronchus anastomosed end to end to the proxima? trachea. After an upper lobectomy the right intermediate bronchus was anastomosed end to side with the left main bronchus. During the reconstruction anaesthesia was main

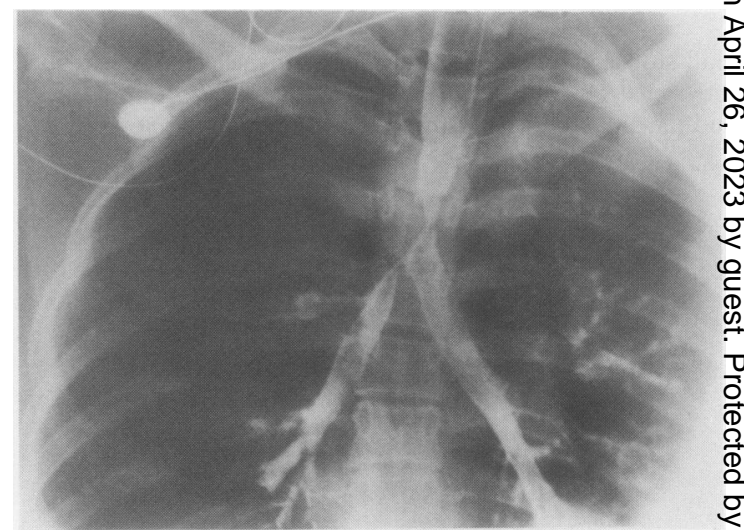

Bronchogram showing stenosis of the lower trachea and the right main bronchus. 
tained with jet ventilation via the left lung. The patient recovered uneventfully and was discharged on the 15 th day after operation. Bronchoscopy, spirometry (FEV, 1.85 1, FVC $\left.2 \cdot 21, \mathrm{FEV}_{1} / \mathrm{FVC} 84 \%\right)$, and a flow-volume loop (3.31/s) performed six months after the operation showed the trachea and bronchi to be of adequate calibre. One year after the surgery and three months after stopping antituberculosis treatment the patient remains symptom free and works as a clerk.

\section{Discussion}

Reports of tracheobronchial tuberculosis are not uncommon $^{3-5}$ but instances of such lesions progressing to become symptomatic and requiring surgery are rare. ${ }^{67}$ The inability to maintain securely even an infant endotracheal tube in our patient necessitated a resection as an emergency operation. This might have been avoided had adequate notice been taken of the wheeze and exertional dyspnoea that the patient had noticed for about a month before presenting to us. As the full extent of the disease was not appreciated at the time of the first procedure a second operation became mandatory.
Neither specific chemotherapy nor corticosteroid treatment influenced the progression of the fibrotic process.

\section{References}

1 Salkin D, Cadden AV, Edison RC.The natural history of tuberculous tracheobronchitis. Am Rev Tuberc 1943;47:351-69.

2 Grillo HC. Tracheal reconstruction. In: Sabiston DC, Spencer FC, eds. Gibbon's Surgery of the chest. 4th ed. Philadelphia: WB Saunders, 1983:263.

3 Pierson DJ, Lakshminarayan MB, Petty TL. Endobronchial tuberculosis. Chest 1973;64:537-9.

4 Albert RK, Petty TL. Endobronchial tuberculosis progressing to bronchial stenosis. Chest 1976;70:537-9.

5 Ip MSM, So SY, Lam WK, Mok CK: Endobronchial tuberculosis revisited. Chest 1986;89:727-30.

6 Caligiuri PA, Banner AS, Jensik RJ. Tuberculous main-stem bronchial stenosis treated with sleeve resection. Arch Intern Med 1984;144:1302-4.

7 Mellen H, Boye NP, Arnkvaern R, Fjeld NBJ. Stenotic tuberculous tracheitis treated with resection and anastomosis. Eur $J$ Respir Dis 1986;68:224-5. 